\title{
SITUAÇÃO DOS SERVIÇOS OFICIAIS DE SAÚDE PÚBLICA NA REGIÃO DO GRANDE SÃO PAULO EM $1967^{(1)}$
}

João YUNES

\begin{abstract}
YUNES, J. - Situação dos serviços oficiais de saúde pública na regiāo do Grande São Paulo em 1967. Rev. Saúde públ., S. Paulo, 3(1):51-58, jun. 1969.

RESUMo - Estudou-se o Plano Diretor de São Paulo tendo sido verificado que, para a Região do Grande São Paulo, 96,5\% das Unidades Sanitárias representadas por Centros, Postos ou Sub-Centros de Saúde são estaduais. A participação estadual é de $100 \%$ para o município de São Paulo. Para êste município verificou-se a relação de um Centro de Saúdè para cada 400.000 habitantes e um Pôsto de Saúde para cada 160.000 habitantes. Esta relação para o Grande São Paulo foi, respectivamente, de um Centro de Saúde para cada 270.000 habitantes e um Pôsto de Saúde para cada 120.000 habitantes, sendo menor o número destas unidades sanitárias exatamente nas áreas em que as condiçōes sócio-econômicas são piores. Em 11 municípios dos 38 que compõem a área do Grande São Paulo verificou-se ausência dêsse tỉpo de serviço. Em relação à Assistência Materno-Infantil, o Estado participa com 77,2\% dos postos existentes e para o município de São Paulo esta relação é de $73,8 \%$, verificando-se um Pôsto para cada 33.000 habitantes no município e um para cada 30.000 no Grande São Paulo. Em 60\% dos Postos Materno-Infantis localizados no município não se presta assistência pré-natal, atingindo na região do Grande São Paulo a cifra de $66 \%$. Verificou-se que não há participação da Prefeitura na assistência especializada, estando o Serviço de Psiquiatria em situação calamitosa, com apenas dois ambulatórios. O atendimento ao doente de lepra é caracterizado pela carência de pessoal médico e para-médico. O atendimento aos pacientes tuberculosos é, entre os serviços especializados, o que se encontra em melhores condições.
\end{abstract}

Os serviços oficiais de Saúde Pública se dividem em assistência médica sanitária geral e assistência médica sanitária especializada. Á assistência médica sanitária geral é prestada através das unidades sanitárias representadas pelos Centros de Saúde, Sub-Centros, Postos de Con- sultas médicas, Postos de Higiene Materno-Infantil ou de Puericultura e a assistência médica sanitária especializada através dos Dispensários de Hanseníase, Tubérculose e Serviços de Psiquiatria. A análise destas unidades sanitárias será feita segundo a sua distribuição, grau de

Recebido para publicação em 28-2-1969.

(1) Do Centro de Estudos de Dinâmica Populacional, anexo ao Departamento de Estatistica Aplicada, da Faculdade de Higiene e Saúde Pública da USP. Do Grupo de Pediatria Preventiva e Social da Cadeira de Pediatria e Puericultura da Faculdade de Medicina da USP - São Paulo, Brasil. 
YUNES, J. - Situação dos serviços oficiais de saúde pública na região do Grande são Paulo em 1967. Rev. Saúde públ., S. Paulo, 3(1):51-58, jun. 1969.

atendimento e padrões dos serviços prestados para o município de São Paulo e área do Grande São Paulo, que engloba 38 municípios com uma população aproximada de 7 milhões de habitantes.

\section{Assistência Médica Sanitária Geral}

\subsection{Postos de Saúde}

$\mathrm{Na}$ área do Grande São Paulo Oficial existem 86 unidades sanitárias de tipo Postos de Saúde (Centros, Postos e Sub-Centros) dos quais $83(96,5 \%)$ são estaduais e sòmente $3(3,5 \%)$ são municipais. Dêsse total, $54,(62,8 \%)$ estão localizados no Município de São Paulo, todos pertencentes ao Govêrno Estadual, não participando a Prefeitura com nenhuma unidade de atendimento geral. Esta situação é ilustrada pela Tabela 1 .

A medida que se caminha do Município de São Paulo para as regiões periféricas do Grande São Paulo, observa-se que o número de unidades sanitárias diminuem exatamente nas áreas em que as condições sócio-econômicas são piores e também onde existem menor número de profissionais médicos e para-médicos. Esta situação obriga a população a buscar os recursos médicos assistenciais no Município de São Paulo, sobrecarregando os serviços oficiais de Saúde Pública e com. prometendo ainda mais a qualidade do seu atendimento.
Estas unidades sanitárias prestam diferentes serviços, de acôrdo com o tipo de pôsto, cabendo aos Centros de Saúde a. assistência mais completa e especializada e aos Sub-Centros e outros tipos o atendimento que exige menor especialização. De maneira geral os serviços prestados por estas unidades sanitárias podem ser sub-divididos, de acôrdo com o critério adotado pela Secretaria da Saúde, em três. tipos:

$\left.1 .^{\circ}\right)$, Serviços Básicos: Higiene Pré-Natal, Higiene Infantil, Higiene Pré-Escolar e Exames médicos periódicos.

2. ${ }^{\circ}$ Serviços Especializados: Buco-Dentário, Dermatológico, Higiene Mental, Higiene Pré-Nupcial, Oftalmologia, Otorrinolaringologia e Sífilis.

$\left.3 .^{\circ}\right)$ Serviços Complementares: Educação Sanitária, Atestados, Imunização, Enfermagem, Lactário, Laboratório, Exames Radiológicos e Saneamento.

Pelo volume das principais atividades desenvolvidas por essas unidades durante o primeiro semestre de 1967, pode-se, de certa maneira, analisar o seu rendimento através do número médio de pacientes atendidos por médico. Essa razão foi de 5,7 por hora, adotando-se em média 20 dias úteis por mês, incluindo-se os pacientes de retôrno e admitindo que o médico cumpra o seu horário integralmen.

T A B ELA 1

Grande São Paulo - Participação dos Postos de Assistência Médica Geral por Entidade Mantenedora - 1967

\begin{tabular}{|c|c|c|c|c|c|}
\hline \multirow{2}{*}{$\mathrm{R}$ e g i ã o } & \multirow{2}{*}{ Total } & \multicolumn{2}{|c|}{ Es t a d u a 1} & \multicolumn{2}{|c|}{ M u n i c i p a l } \\
\hline & & $\begin{array}{c}\text { N.os } \\
\text { Absolutos }\end{array}$ & $\%$ & $\begin{array}{c}\text { N.os } \\
\text { Absolutos }\end{array}$ & $\%$ \\
\hline Municfpio de São Paulo & 54 & 54 & 100,0 & 一 & - \\
\hline Grande São Paulo & 86 & 83 & 96,5 & 3 & 3,5 \\
\hline
\end{tabular}

FONTE: Secretaria da Saúde Pública do Estado de São Paulo - São Paulo, Brasil. 
YUNES, J. - Situação dos serviços officiais de saúde pública na região do Grande São Paulo em 1967. Rev. Saúde públ., S. Paulo, 3(1):51-58, jun. 1969.

te. Por êsse resultado pode-se verificar que o rendimento apresentado não é satisfatório, agravando-se ainda mais quando se nota a falta de pessoal para-médico qualificado e a precariedade de recursos materiais.

O padrão atual (Tabela 2) está abaixo do teòricamente recomendado para as grandes metrópoles, em virtude do número de habitantes, por pôsto, ser muito elevado.

Para os Centros de Saúde recomenda-se uma unidade para cada 200.000 habitantes, em média. Para os Postos de Saúde recomenda-se uma unidade para cada 100.000 habitantes. Por outro lado, a definição dêstes padrões deve estar condicionada a outras variáveis tais como densidade populacional, transporte, distribuição da população por certas características (sexo, idade, classe social, etc.), incidência e prevalência de morbidade e muitos outros fatôres. Tomando-se como correlação apenas a população, a situação atual para os centros de saúde é de $1: 400.000$ e 1:270.000, respectivamente, para o Município e o Grande São Paulo; e para os Postos de Saúde ou Sub-Centros é de $1: 160.000$ e $1: 120.000$, respectivamente, para as mesmas regiōes. Esse fato torna-se mais grave quando se verifica que há concentração excessiva de postos de saúde em alguns locais e ausência quase que total em outros, principalmente, na periferia do Grande São Paulo, onde se observa a ausência dêsse tipo de unidade em 11 municípios (Arujá, Biritiba-Mirim, Brás Cubas, Carapicuiba, Cajamar, Embu-Guaçú, Francisco Morato, Jandira, Juquitiba, Rio Grande da Serra, Salesópolis), fazendo com que aproximadamente 100.000 pessoas não disponham de nenhuma assistência médica por parte do poder público. Isto explica, em parte, porque êstes municípios periféricos são obrigados a recorrer aos municípios vizinhos ou do Município de São Paulo para receberem alguma forma de assistência médica. Concluimos, portanto, que para a área do Grande São Paulo, não só os padrões estão abaixo do costumeiramente recomendado, como também inclui muitos municípios sem nenhuma assistência médica.

\subsection{Postos de Assistência Materno-Infantil}

A rêde dêste tipo de serviço (Tabela 3 ) é composta de 236 Postos de Assistência Materno-Infantil ou de Puericultura inseridos no Grande São Paulo, dos quais 174

T A B E L A 2

Grande São Paulo - Participação dos Postos de Assistência Médica Geral por Entidade Mantenedora - 1967

\begin{tabular}{|c|c|c|c|c|}
\hline \multirow[b]{2}{*}{ R e g i a o } & \multicolumn{2}{|c|}{ Centro de Saúde } & \multicolumn{2}{|c|}{ Sub-Centro ou Pôsto de Saúde } \\
\hline & $\begin{array}{l}\text { N.os de } \\
\text { Unidades }\end{array}$ & $\begin{array}{c}\text { Pop. teòrica- } \\
\text { mente atendida } \\
\text { p/Unid. }\end{array}$ & $\begin{array}{l}\text { N.os de } \\
\text { Unidades }\end{array}$ & $\begin{array}{l}\text { Pop. teòrica- } \\
\text { mente atendida } \\
\text { p/Untd. }\end{array}$ \\
\hline Municipio de São Paulo & 17 & 400.000 & 34 & 160.000 \\
\hline Grande São Paulo & 25 & 270.000 & 58 & 120.000 \\
\hline
\end{tabular}

FONTE dos dados brutos: Secretaría da Saúde Püblica do Estado de São Paulo, São Paulo - Brasil. 
YUNES, J. - Situação dos serviços oficiais de saúde pública na região do Grande São Paulo em 1967. Rev. Saúde públ., S. Paulo, 3(1):51-58, jun. 1969.

TA B E L A 3

Grande São Paulo - Distribuição dos Postos de Higiene Materno-Infantil por Entidade Mantenedora - 1967

\begin{tabular}{c|c|c|c|c|c}
\hline & \multirow{2}{*}{ R e g i ã o } & \multicolumn{2}{|c|}{ E s t a d u a 1 } & \multicolumn{2}{|c}{ M u n i c i p a l } \\
\cline { 3 - 6 } & & $\begin{array}{c}\text { Nos } \\
\text { Absolutos }\end{array}$ & $\%$ & $\begin{array}{c}\text { N.os } \\
\text { Absolutos }\end{array}$ & $\%$ \\
\hline Município de São Paulo & 162 & 125 & 77,2 & 37 & 22,8 \\
Grande São Paulo & 236 & 174 & 73,8 & 62 & 26,2 \\
\hline
\end{tabular}

FONTE: Departamento Estadual de Estatistica (DEE) - Departamento Estadual da Criança (DEC) - Departamento de Assistência à Infância e Maternidade (DAIM) (São Pau10 - Brasil).

$(73,7 \%)$ são de responsabilidade estadual e $62(26,3 \%)$ de responsabilidade dos municípios integrados nesta área. Dêsse total, 162 unidades $(68,6 \%)$ estão localizados no Município de São Paulo, das quais $125(77,2 \%)$ pertencem ao Estado e $37(22,8 \%)$ à Prefeitura.

Essas unidades, teòricamente, são encarregadas da Higiene Infantil, Higiene Pré-Natal, Pré-Escolar e assistência odontológica à gestante e às crianças. $\mathrm{Na}$ realidade, a maioria dos Postos de Puericultura não prestam os serviços de higiene pré-natal. A Tabela 4 permite constatar essa realidade, onde se observa que no Município de São Paulo 60,5\% dos postos não possuem higiene pré-natal e no Grande São Paulo esta proporção é de $66,1 \%$. Dos 38 municípios que compõem a regiăo do Grande São Paulo, 21 $(55,3 \%)$ não oferecem nenhum atendimento pré-natal. Este fato explica em parte $o$ alto coeficiente de mortalidade neo-natal (34 óbitos/1.000 nascidos para o Município de São Paulo em 1966).

Pelo volume de atendimento prestado pelos Postos de Puericultura durante o ano de 1967, pode-se de certa maneira

TA B E L A 4

Grande São Paulo - Distribuição dos Postos de Higiene Infantil e dos Municípios sem Serviço Pré-Natal segundo as Regiōes - 1967

\begin{tabular}{|c|c|c|c|c|c|c|}
\hline \multirow[b]{2}{*}{$R$ e $g$ i $\tilde{a} o$} & \multicolumn{3}{|c|}{ Postos de Higiene Infantil } & \multicolumn{3}{|c|}{ Mun i cipios } \\
\hline & $\begin{array}{l}\text { Unidades } \\
\text { Existentes }\end{array}$ & $\begin{array}{l}\text { Unidades } \\
\text { sem } \\
\text { Pré-Natal }\end{array}$ & $\%$ & Existentes & $\begin{array}{c}\text { Sem } \\
\text { Pré-Natal }\end{array}$ & $\%$ \\
\hline Municipio de São Paulo & 162 & 98 & 60,5 & 1 & - & - \\
\hline Grancio São Paulo & 236 & 156 & 66,1 & 38 & 21 & 55,3 \\
\hline
\end{tabular}

FONTE: DEE - DEC - DAIM. 
YUNES, J. - Situação dos serviços oficlais de saúde pública na região do Grande São Paulo em 1967. Rev. Saúde públ., S. Paulo, 3(1):51-58, jun. 1969.

analisar o seu rendimento através do número médio de pacientes atendidos por médico. Essa razão foi de 3,6 e 4 por hora, respectivamente, para as unidades de responsabilidade municipal e estadual. Isto nos permite afirmar que o rendimento apresentado por êstes serviços é bastante precário, acrescido do baixo padrão qualitativo do serviço prestado de uma maneira geral, devido principalmente à carência de material e pessoal qualificado.

Quanto à relação entre a população atendida e a rêde existente (Tabela 5) constatamos que para cada 30.000 habitantes da área do Grande São Paulo e 33.000 do município existe um Pôsto de Puericultura, satisfazendo plenamente o padrão quantitativo que é de um para 50.000 . Para os serviços que oferecem pré-natal, essa relação é de 85.000 e 80.000 habitantes por unidade dêste tipo para as áreas, respectivamente, do Grande São Paulo e do Município, não obedecendo ao padrão geralmente recomendado.

Quanto aos padróes quantitativos, conclui-se que a situação é bastante satisfatória, estando mesmo acima das relações recomendadas. No entanto, ao se considerar que a maioria não possui assistência pré-natal, a relação de população atendida por unidades com serviços completos passa a ser aquém dos padrões recomendados.
Finalmente, há que considerar que a localização dêsses equipamentos, como em todos os outros setores sociais e de utilidade pública, há concentração exagerada em algumas áreas mais centrais, notando-se, como sempre, menor atendimento das áreas periféricas, onde 8 municípios do Grande São Paulo (Arujá, Barueri, Biritiba-Mirim, Cajamar, Francisco Morato, Jandira, Juquitiba, Rio Grande da Serra) não possuem nenhum Pôsto de Higiene Materno-Infantil, fazendo com que, aproximadamente, 80.000 habitantes dessas localidades não tenham êsse tipo de assistência. $\mathrm{O}$ fato é ainda mais grave, pois $55 \%$ dos municípios não possuem atendimento pré-natal.

\section{Assistência Médica Sanitária EsPECIALIZADA}

A assistência médica especializada no que diz respeito aos serviços de Hanseniase, Psiquiatria e Tuberculose, é prestada apenas pelo Estado. O Município, até o presente momento, é omisso nesse tipo de assistência.

$\mathrm{Na}$ região do Grande São Paulo, de acôrdo com a Tabela 6 , existem 16 dispensários de Hanseníase, dos quais 13 . $(81,2 \%)$ estão localizados no Município de São Paulo. Para o atendimento psiquiátrico público, a área do Grande São.

T A B ELA 5

Grande São Paulo - População teòricamente atendida pelos Serviços de Higiene Materno-Infantil segundo os Tipos e as Regióes - 1967

\begin{tabular}{|c|c|c|c|c|}
\hline \multirow{2}{*}{$R$ e g i a o } & \multicolumn{2}{|c|}{ Postos de Higiene Infantil } & \multicolumn{2}{|c|}{$\begin{array}{c}\text { Pôsto de Higiene Infantil com } \\
\text { Higiene Pré-Natal }\end{array}$} \\
\hline & $\begin{array}{l}\text { N.os de } \\
\text { Unidades }\end{array}$ & $\begin{array}{l}\text { Pop. Teòrica- } \\
\text { mente atendida } \\
\text { p/Unid. }\end{array}$ & $\begin{array}{l}\text { N.os de } \\
\text { Unidades }\end{array}$ & $\begin{array}{l}\text { Pop. Teobrica- } \\
\text { mente atendida } \\
\text { p/Unid. }\end{array}$ \\
\hline Municipio de São Paulo & 162 & 33.000 & 64 & 80.000 \\
\hline Grande São Paulo & 236 & 30.000 & 80 & 85.000 \\
\hline
\end{tabular}

FONTE dos dados brutos: DEC - DAIM - DEE. 
YUNES, J. - Situacão dos serviços oficiais de saúde pública na região do Grande São Paulo em 1967. Rev. Saíde pübl., S. Paulo, 3(1):51-58, jun. 1969.

T A B E L A 6

Grande São Paulo - Distribuição das Unidades de Saúde Públíca de Assistência Médica Especializada segundo as Regiões e a População teòricamente atendida — 1967

\begin{tabular}{|c|c|c|c|c|c|c|}
\hline \multirow[b]{2}{*}{$R$ e g $\mathbf{i} \tilde{a} o$} & \multicolumn{2}{|c|}{ Lepra } & \multicolumn{2}{|c|}{ Psiquiatria } & \multicolumn{2}{|c|}{ Tuberculose } \\
\hline & $\begin{array}{l}\text { N. }{ }^{\circ} \text { de } \\
\text { Unidades }\end{array}$ & $\begin{array}{l}\text { População } \\
\text { coberta }\end{array}$ & $\begin{array}{l}\text { N.o de } \\
\text { Unidades }\end{array}$ & $\begin{array}{l}\text { População } \\
\text { coberta }\end{array}$ & $\begin{array}{l}\text { N.o de } \\
\text { Unidades }\end{array}$ & $\begin{array}{l}\text { População } \\
\text { coberta }\end{array}$ \\
\hline Município de São Paulo & 13 & 393.000 & 2 & 2.558 .000 & 17 & 301.000 \\
\hline Grande São Paulo & 16 & 425.000 & 2 & 3.400 .000 & 22 & 309.000 \\
\hline
\end{tabular}

FONTE dos dados brutos: DEE e Secretaria de Saúde Pública do Estado de São Paulo.

Paulo só possui dois ambulatórios, ambos localizados no Município de São Paulo. Dos 22 dispensários de Tuberculose existentes no Grande São Paulo, $17(77,2 \%)$ estão localizados naquele Município.

De acôrdo com informações do Departamento de Dermatologia Sanitária (antigamente Departamento de Profilaxia da Lepra), o número total de pacientes controlados pelos dispensários da Capital era, para o ano de 1967 , de 32.570 pessoas, das quais 10.166 categorizadas como doentes e 22.404 como comunicantes. $O$ atendimento é caracterizado pela carência de pessoal médico, educadores sanitários, pessoal auxiliar, medicamentos específicos e inespecíficos, adestramentos técnicos, o que conduz a um comprometimento qualitativo, agravado pela sobrecarga de do. entes vindos de outros Estados e do Interior.

Dentre os serviços especializados, o de psiquiatria é o que apresenta a situação mais calamitosa. Possui, como já foi visto, sòmente dois ambulatórios estaduais para atender tôda a região do Grande São Paulo e mesmo do interior do Estado. O atendimento anual é de cêrca de 46.000 pacientes, entre novos e antigos. Diante de tal situação não resta a menor dúvida de que o padrão de serviço qualitativo e quantitativo está altamente comprometido, dada a carência de recursos de instalação e pessoal e a grande sobrecarga de pacientes que procuram êste serviço, vindos de outras áreas.

$O$ atendimento de pacientes tuberculosos é prestado pela Divisão de Serviços de Tuberculose e entre os serviços especializados, é o que se encontra em melhores condições. As atividades dessa divisão se prendem não sòmente aos Dispensários mas também a Unidades Móveis de Abreugrafia e Centro de Triagem dos Serviços de Imigração.

A Tuberculose representa ainda um problema sério de Saúde Pública para o Município e o Grande São Paulo. Sòmente em 1966 foram prestadas 156.599 consultas, das quais 78.229 para diagnóstico e 78.370 para tratamento. $O$ número de doentes em tratamento atingiu a 17.555 pacientes.

Das abreugrafias realizadas no ano de 1964, pela Unidades Móveis de Abreugrafia na área do Grande São Paulo, 1,33\% revelavam diagnósticos prováveis de Tuberculose, enquanto que daquelas realizadas para o Centro de Triagem do Serviço de Imigração, em 1966, 1,49\% foram considerados suspeitos e $0,88 \%$ confirmaram diagnóstico de Tuberculose. Os municípios que apresentaram taxas mais elevadas de provável diagnóstico foram, por ordem decrescente: Taboão da Serra, com $4,76 \%$; Embu $(2,63 \%)$; Mogi das Cru- 
YUNES, J. - Situação dos serviços oficiais de saúde pública na região do Grande São Paulo em 1967. Rev. Saúde públ., S. Paulo, 3(1):51-58, jun. 1969.

zes $(1,94 \%)$; Guararema $(1,48 \%)$ e Salesópolis, com $1,48 \%$. Os outros municípios do Grande São Paulo apresentaram taxa menor de $1,0 \%$.

A incidência ainda alta de Tuberculose em nosso meio, de acôrdo com o volume de atendimentos verificados, reflete que uma parcela considerável da população ainda vive em condições infra-humanas, o que coloca esta moléstia como a primeira causa de morte entre as doenças transmissíveis.

$\mathrm{Na}$ Tabela 6 resumimos o padrão atual existente, isto é, a população teòricamente coberta pelos diferentes tipos de Unidades Sanitárias Especializadas. A primeira constatação que nos é permitida fazer é que para a Região do Grande São Paulo existem 20 municípios $(52,7 \%)$ que não possuem nenhum tipo de unidade especializada, a saber: Carapicuiba, Rio Grande da Serra, Biritiba-Mirim, Cotia, Itapevi, Jandira, Guararema, Itapecerica da Serra, Embu, Embu-Guaçu, Juquitiba, Mairiporã, Franco da Rocha, Caieiras, Francisco Morato, Salesópolis, Santa Isabel, Arujá, Santana do Parnaíba, Cajamar, Pirapora do Bom Jesus. A segunda e a mais calamitosa constatação é em relação ao problema da assistência ao psicopata, em que na região do Grande São Paulo existe a proporção de 3.400 .000 habitantes para cada ambulatório de psiquiatria, que perfazem como já vimos, o total de sòmente duas unidades para uma população de 7 milhões de habitantes.

Esta situação se torna mais caótica quanto sabemos que estas unidades atendem muitas vêzes doentes do interior de São Paulo e mesmo de outros Estados. Para o município de São Paulo, o padrão é de 2.557.928 habitantes por unidade ambulatorial de psiquiatria.

Para o atendimento do doente de lepra, o padrão quantitativo apresenta-se aceitável, uma vez que existe para o Grande São Paulo uma população teòricamente coberta de 425.000 habitantes por unidade. Esta proporção é de 393.000 para - Município de São Paulo.
0 padrão quantitativo para o atendimento do doente tuberculoso apresenta entre os padrões das unidades especializadas - melhor coeficiente pois para cada 309.000 habitantes do Grande São Paulo existe um dispensário de tuberculose. Esta proporção é de 301.000 para o Município de São Paulo.

Os padróes de atendimento quantitativo e qualitativo das unidades especializadas, que hoje estão bastante abaixo do desejável, poderão ser muito aperfeiçoados à medida que se ampliarem e se integrarem nas unidades sanitárias polivantes, atual filosofia de ambas as Secretarias de Higiene da Prefeitura e de Saúde do Estado de São Paulo.

YUNES, J. - Situation of public health service in the Greater São Paulo, Brazil, in 1967. Rev. Sauide puibl., S. Paulo, 3(1) :51-58, jun. 1969.

Summary - This summary refers to a study carried out for the "Plano Diretor de São Paulo", including the area of the "Greater São Paulo". 96.5\% of the Health Centers and Subsidiary Centers are state agencies. The participation of the state government in this field, in the City of São Paulo is $100 \%$. In the same area there is a ratio of one Health Center to every 400,000 inhabitants and one Subsidiary Health Center to every 160,000 inhabitants. In the area of "Greater São Paulo" this relation is one Health Center to 270,000 inhabitants and one Subsidiary Health Center to every 120,000 inhabitants. There are less Centers and Subsidiary Centers in the areas of lower social economic conditions. In 11 towns of the 38 which compose "Greater São Paulo", there is not even one Sanitary Unit. $77.2 \%$ of the Centers of Maternal and Child Care are state agencies. In the City of São Paulo, the relation is one Maternal and Child Care Center to every 33,000 inhabitants and in the area of "Greater São Paulo", one to every 30,000 inhabitants. $60 \%$ of these Centers in 
YUNES, J. - Situação dos serviços oficiais de saúde pública na região do Grande são Paulo em 1967. Rev. Saúde pribl., S. Paulo, 3(1):51-58, jun. 1969.

the City of São Paulo and $66 \%$ in "Greater São Paulo" do not offer pre-natal care. The county government does not participate in the specialized care to individuals. the psychiatric sector being in critical condition with only two out-patient clinics. There is a lack of personnel (doctors and technical assistants) in the Centers which offer medical care to lepers. The care offered to patients with tuberculosis is among the best considering all the units. 